\title{
Adapting and Testing the Feasibility of a Prenatal Intervention for Low-Income Parents
}

The transition to parenthood can be a difficult time for many new parents. The perinatal period, defined as the period before, during, and following pregnancy, often corresponds with changes in family roles and responsibilities, coupled with fluctuations in hormone levels that occur during pregnancy. These changes in family dynamics and hormone levels have been linked to increases in stress and depression in pregnant women. ${ }^{1-2}$ Both stress and depression are risk factors for mothers' mental health and child development. Moreover, significant mental health disparities exist based on social class, race, and ethnicity. Low-income mothers, for example, experience significantly higher rates of perinatal stress and depression (up to 50\%) than middle-class mothers (10-12\%). ${ }^{3}$ Increased levels of stress and depression can have detrimental effects on the mental health of the mother, father, and on the healthy development of the infant.

New research suggests that the optimal time to address maternal-stress and depression is early in pregnancy, between 12-25 weeks; ${ }^{4}$ however, there are few evidencebased interventions aimed at reducing depression and stress in these early months of pregnancy. There is also a lack of community-based interventions targeting lowincome pregnant mothers and their partners, despite research evidence regarding the importance of including fathers and partners in early intervention efforts.

To address this need, UMass Amherst and the UMass Medical School partnered with Square One and the Children's Trust on a pilot study to promote the mental health and co-parenting relationships of underserved, lowincome parents and their partners. Adapting and Testing the Feasibility of a Prenatal Intervention for Low-Income Parents will adapt and test the feasibility of a group-based intervention called Choices in Childbirth \& Co-Parenting (3CP) aimed at reducing depression and stress among low-

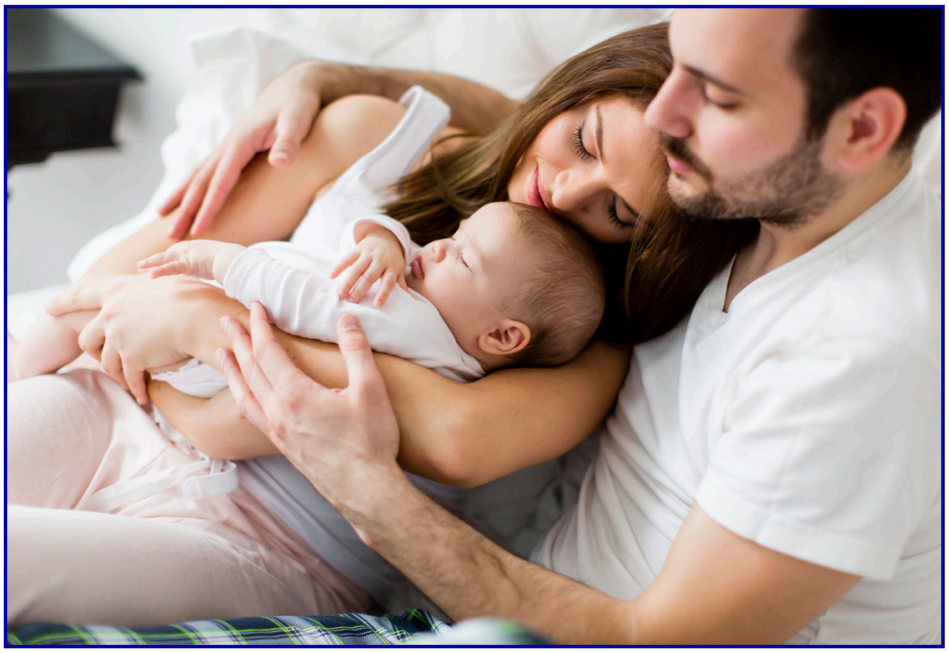

income new mothers and their partners early in pregnancy. The specific aims of the project include:

1. Adapt the $3 \mathrm{CP}$ curriculum, through expert consultation and feedback from low-income new mothers, their partners and program educators, regarding acceptability and usefulness

2. Test the feasibility and acceptability of the revised $3 \mathrm{CP}$ program and assessment procedures in a pilot study with low-income, first-time parents in Springfield, Massachusetts; and

3. Analyze preliminary pilot data to assess changes in depression and stress (both psychosocial and biological) for mothers and their partners and potential enhancements to the co-parental relationship among prenatal women and their partners.

Next steps will include a randomized controlled trial of the adapted 3CP program with a larger cohort of low-income, prenatal parents. This research should lead to a sustainable intervention that brings needed resources to low-income new parents who have a high risk for perinatal stress and depression.

Research Team: Co-PIs: Maureen Perry-Jenkins, PhD, Professor of Psychological and Brain Sciences, Director of Center for Research on Families, UMass Amherst; Nancy Byatt, DO, MS, MBA, Associate Professor, Dept. of Psychiatry and Obstetrics and Gynecology, UMass Medical School; Co-Is: Sally Powers, EdD, Professor of Psychological and Brain Sciences, Associate Dean for Faculty and Research, College of Natural Sciences, UMass Amherst; Joni Beck Brewer, LICSW, Vice-President of Family Services, Square One, Springfield MA. Funding: UMMS CCTS. Time Frame: 4/1/2017-6/30/2018. Study Contact: Maureen Perry-Jenkins: mpj@psych.umass.edu. 


\section{References}

1. Field, T., Diego, M., Dieter, J., Hernandez-Reif, M., Schanberg, S., Kuhn, C., Yando, R., \& Bendell, D. (2004). Prenatal depression effects on the fetus and the newborn. Infant Behavior and Development, 27(2), 216-229. doi:10.1016/j.infbeh.2003.09.010

2. Nierop, A., Bratsikas, A., Zimmermann, R., \& Ehlert, U. (2006). Are stress-induced cortisol changes during pregnancy associated with postpartum depressive symptoms? Psychosomatic Medicine, 68(6), 931-937.

doi:10.1097/01.psy.0000244385.93141.3b

3. Chaudron, L. H., Szilagyi, P. G., Tang, W., Anson, E., Talbot, N. L., Wadkins, H. I. M., Tu, X., \& Wisner, K. L. (2010). Accuracy of depression screening tools for identifying postpartum depression among urban mothers. Pediatrics, 125(3), e609-e617. doi:10.1542/peds.2008-3261

4. Dunkel Schetter, C., \& Tanner, L. (2012). Anxiety, depression and stress in pregnancy: Implications for mothers, children, research, and practice. Current Opinion in Psychiatry, 25(2), 141-148. doi:10.1097/YCO.0b013e3283503680 